\title{
EXPERIMENTAL APPROACH TO EVALUATION OF FIBER CONTRIBUTION IN FRC
}

\author{
MINORU KUNIEDA* AND RYOTA MORI ${ }^{\dagger}$ \\ *Gifu University \\ Gifu, JAPAN \\ e-mail: kunieda@gifu-u.ac.jp \\ ${ }^{\dagger}$ Gifu University \\ Gifu, JAPAN \\ e-mail: u3121030@edu.gifu-u.ac.jp
}

Key words: FRC, Fiber Bridging, Shear Capacity, Polypropylene, Melting

\begin{abstract}
Short fibers such as steel, Polyvinyl Alcohol (PVA), Polypropylene (PP) and Polyethylene (PE) can contribute to the increase of not only tensile capacity but also shear capacity in Fiber Reinforced Concrete (FRC). There are many design guideline for FRC to estimate the fiber contribution. At a crack surface in FRC subjected to shear load, short fibers can resist shear deformation in addition to interlocking of aggregate and reinforcement. For reasonable design, exact fiber contribution should be evaluated experimentally. In this paper, fiber contribution was extracted experimentally by using melting method. In the experiment, FRC with PP fiber was used, and bending or shear crack was induced in the specimens. After that, cracked specimens were exposed to high temperature over 500 degrees, and only PP fiber bridging a crack was melted. It was clarified that the evaluated fiber contribution through this manner was much higher than that of ordinary calculation method.
\end{abstract}

\section{INTRODUCTION}

A wide variety of fiber reinforced concrete (FRC) has been developed, and it enhances mechanical properties of cementitious composites such as strength, toughness, durability and so forth. Short fibers such as steel, Polyvinyl Alcohol (PVA), Polypropylene (PP) and Polyethylene (PE) can contribute to the increase of not only tensile capacity but also shear capacity in Fiber Reinforced Concrete (FRC). There are many design guideline for FRC to estimate the fiber contribution in cracked FRC [1-2]. At a crack surface in FRC subjected to shear load, short fibers can resist shear deformation, in addition to interlocking of aggregate and resistance of steel reinforcement. For a reasonable design, exact fiber contribution should be evaluated experimentally. In this paper, fiber contribution was extracted experimentally by using heating process. In the experiment, FRC with PP fiber having low melting temperature was used, and bending or shear crack was induced in the specimens. After that, cracked specimens were exposed to high temperature over 500 degrees in order to melt PP fibers. Through the above procedure, fiber contribution was confirmed experimentally.

\section{OUTLINE OF EXPERIMENTS}

\subsection{Specimens}

In this study, FRC with polypropylene (PP) fibers (length:30mm, diameter: $0.6 \mathrm{~mm}$ ) were 
Table 1: Mix proportions of used FRC

\begin{tabular}{ccccccccc}
\hline Mix & W/C & s/a & W & C & S & G & Fiber & Ad. \\
\hline $1.0 \%$ & 0.5 & 0.43 & 160 & 320 & 764 & 1017 & 9.1 & 3.2 \\
\hline $1.5 \%$ & 0.5 & 0.43 & 160 & 320 & 764 & 1004 & 13.65 & 3.2 \\
\hline
\end{tabular}

Table 2: Type of specimens

\begin{tabular}{|c|c|c|c|}
\hline Series & $\begin{array}{c}\text { Fiber } \\
\text { content }\end{array}$ & Rebar & $\begin{array}{c}\text { Failure } \\
\text { mode }\end{array}$ \\
\hline $1.0 \mathrm{~N}$ & 1.0 & \multirow{2}{*}{ None } & \multirow{2}{*}{ Flexure } \\
\hline $1.5 \mathrm{~N}$ & 1.5 & & \\
\hline 1.0-D6 & 1.0 & \multirow{2}{*}{ D6 } & \multirow{2}{*}{ Flexure } \\
\hline 1.5-D6 & 1.5 & & \\
\hline 1.0-D13 & 1.0 & \multirow{2}{*}{ D13 } & \multirow{2}{*}{ Shear } \\
\hline 1.5-D13 & 1.5 & & \\
\hline
\end{tabular}

used. Mix proportions of each FRC are shown in Table 1. Water to cement ratio was 0.5. Two kinds of fiber content $(1.0 \%$ and $1.5 \%)$ were selected.

The size of the specimen was $100 \times 100 \mathrm{x}$ $400 \mathrm{~mm}$. As tabulated in Table 2, six kinds of specimen series were prepared. One was plain FRC with no longitudinal reinforcement. Second one was reinfoced FRC with a D6 rebar $\left(f_{\mathrm{y}}=437 \mathrm{MPa}\right)$, in which failure mode of the beam was expected to be flexural failure. And third one was also reinforced FRC with a D13 rebar $\left(f_{\mathrm{y}}=395 \mathrm{MPa}\right)$, in which failure mode was expected to be shear failure eventually. Regarding the reinforced FRC specmens, effective depth was $65 \mathrm{~mm}$, and no shear reinforcement was placed. Number of specimens in each series was five.

\subsection{Loading tests to induce a flexural crack or a shear crack}

To induce a flexural crack or a shear crack in the specimens, four-point bending tests with a span of $300 \mathrm{~mm}$ were adopted.

Conceptual idea to extract a fiber contribution in this research is illustrated in Fig. 1. Flexural loading test was continued up to the displacement of $1.5 \mathrm{~mm}$ in all series, and unloading was carried out. And then, re-loading was also conducted up to the same displacement level $(1.5 \mathrm{~mm})$ just after the unloading. Measured load at the displacement of $1.5 \mathrm{~mm}$ in re-loading was named as $P_{\text {before. }}$ In this stage, flexural cracking occurred in the specimen with D6 rebar, and shear cracking was observed in the specimen with D13 rebar.

After the loading tests, the specimen was placed within an electric furnace. The specimen was burned out at the temperature of 500 degrees during 20 minutes. Note that, heating rate was $25 \mathrm{deg} . / \mathrm{min}$. Through this process, it is assumed that PP fibers across the occurred crack were melted. Since surface concrete in the specimen and/or inside rebar might be damaged by the heating, it is assumed to be sound in this study. Further research and observation are needed for it.

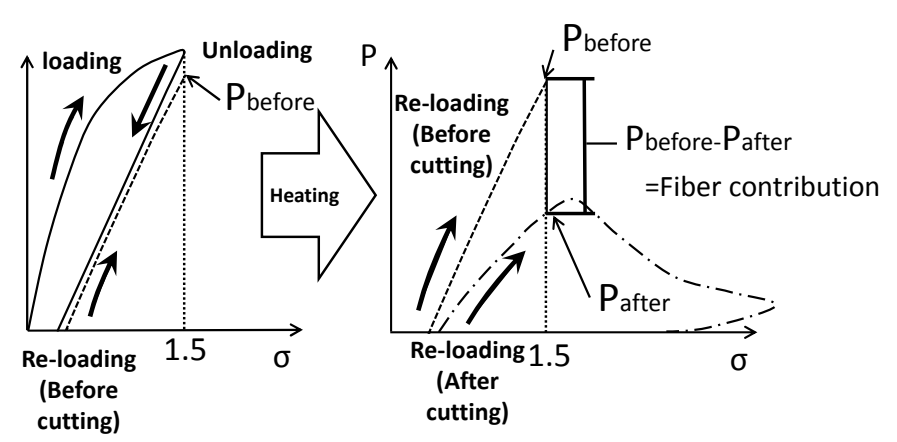

Figure 1: Concept to extract fiber contribution by means of loading test and heating.

After the heating, loading tests were carried out by same manner of initial loading, and load at displacement of $1.5 \mathrm{~mm} P_{\text {after }}$ was also measured. Finally, fiber contribution $P_{\text {fib }}$ can be derived by the following equation.

$P_{\text {fib }}=P_{\text {before }}-P_{\text {after }}$ 


\section{EXPERIMENTAL RESULTS}

\subsection{Residual Tensile Strength of Plain FRC (1.0N and 1.5N series)}

Load-displacement curves of plain FRC before and after the heating process are shown in Figs. 2 and 3. Measured load value at displacement of $1.5 \mathrm{~mm}$ was dramatically decreased by the heating process, and this decrease was assumed to be fiber contribution by disappeared fiber.

Residual tensile strength $F_{t_{-} \text {residual }}$ can be calculated by the obtained fiber contribution of plain FRC. Note that fiber model was used for the calculation, and the position of neutral axis was assumed to be the distance from upper fiber of specimen to crack tip of each specimen. The position of crack depth was confirmed by visual observation.

Obtained $F_{\text {t_residual }}$ is tabulated in Table 3. The values ranging from 1.07 to $1.72 \mathrm{MPa}$ were obtained, and it depends on fiber content.

\subsection{Flexural Capacity of Reinforced FRC (1.0-D6 and 1.5-D6 series)}

In this section, flexural capacity of reinforced FRC beams with D6 rebar, which exhibit flexural failure, is discussed through fiber bridging stress.

Figures 4 and 5 illustrate the loaddisplacement curves of 1.0-D6 and 1.5-D6 series. The fiber contribution, which was represented by the difference between the load before heating and that after heating, was significant, as shown in Table 4.

On the other hand, flexural capacity was calculated by analytical approach. Note that tensile stress of fiber that was obtained by Section 3.1 was used. Following equation was used for the calculation.

$M_{\mathrm{u}}=f_{\mathrm{y}} * A_{\mathrm{s}} *(d-0.33 x)+F_{\mathrm{t} \_ \text {residual }} * l_{\text {crack }} *(0.5 *$

$l_{\text {crack }}+0.66 x$ )

$f_{\mathrm{y}}$ : Yield strength of re-bar

$A_{\mathrm{s}}$ : Area of re-bar

$d$ : Effective depth

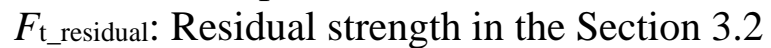

lcrack: Crack length

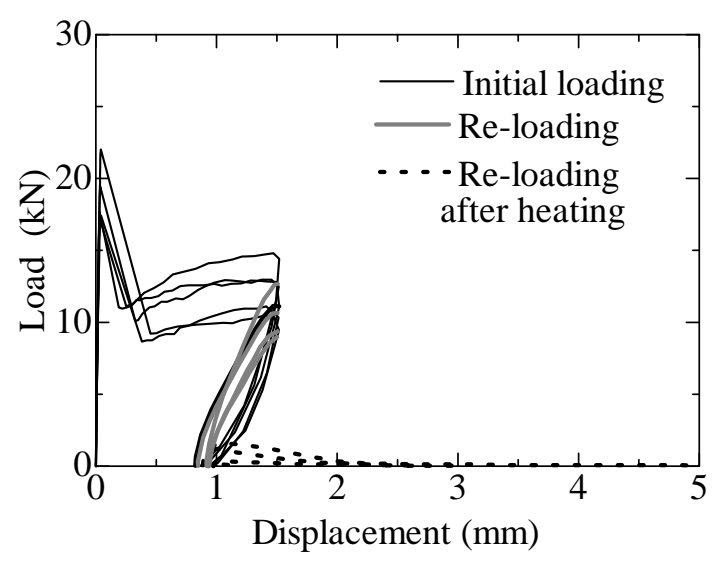

Figure 2: Load-displacement curves of 1.0N Series.

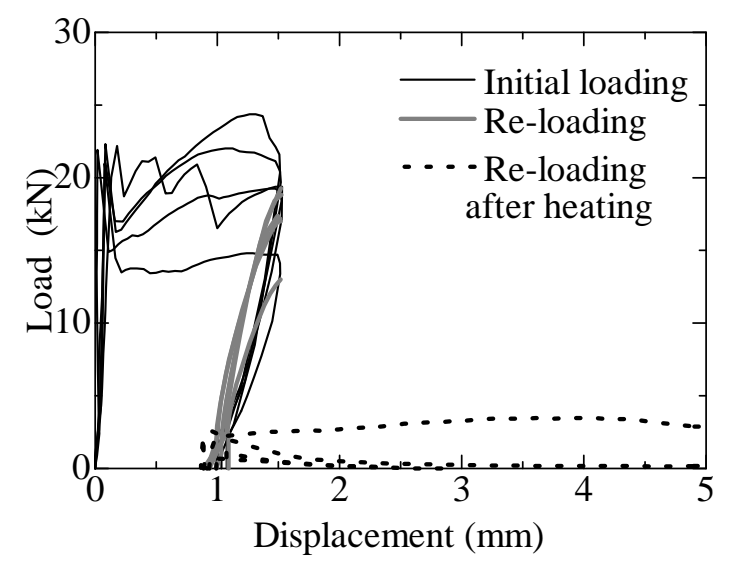

Figure 3: Load-displacement curves of 1.5N Series.

Table 3: Residual strength of plain FRC

\begin{tabular}{|c|c|c|c|}
\hline Series & $\begin{array}{c}\text { Fiber } \\
\text { contribution } \\
(\mathrm{kN})\end{array}$ & $\begin{array}{l}\text { Residual } \\
\text { strength } \\
\text { (MPa) }\end{array}$ & $\begin{array}{c}\text { Averaged } \\
\text { (MPa) }\end{array}$ \\
\hline \multirow{5}{*}{$1.0 \mathrm{~N}$} & 11.10 & 1.131 & \multirow{5}{*}{1.073} \\
\hline & 9.38 & 0.957 & \\
\hline & 10.65 & 1.079 & \\
\hline & 8.98 & 0.907 & \\
\hline & 12.67 & 1.294 & \\
\hline \multirow{5}{*}{$1.5 \mathrm{~N}$} & 19.27 & 1.941 & \multirow{5}{*}{1.722} \\
\hline & 16.99 & 1.725 & \\
\hline & 17.18 & 1.729 & \\
\hline & 13.00 & 1.320 & \\
\hline & 18.82 & 1.895 & \\
\hline
\end{tabular}


Table 4: Residual strength of FRC with D6 rebar (flexural failure)

\begin{tabular}{|c|c|c|c|c|c|}
\hline Series & $\begin{array}{l}\text { Exp. } P_{\max } \\
(\mathrm{kN})\end{array}$ & $\begin{array}{c}\text { Fiber contribution } \\
(\mathrm{kN})\end{array}$ & Cal. $\mathrm{P}_{\max }(\mathrm{kN})$ & Exp. $\mathrm{P}_{\max } /$ Cal. $\mathrm{P}_{\max }$ & Averaged \\
\hline \multirow{5}{*}{ 1.0-D6 } & 29.92 & 27.31 & 34.78 & 0.79 & \multirow{5}{*}{0.78} \\
\hline & 34.27 & 31.26 & 36.57 & 0.85 & \\
\hline & 35.54 & 32.80 & 38.03 & 0.86 & \\
\hline & 33.12 & 30.28 & 38.03 & 0.80 & \\
\hline & 26.46 & 24.34 & 39.14 & 0.62 & \\
\hline \multirow{5}{*}{ 1.5-D6 } & 38.55 & 35.05 & 48.59 & 0.72 & \multirow{5}{*}{0.64} \\
\hline & 33.68 & 30.54 & 50.72 & 0.60 & \\
\hline & 31.29 & 29.07 & 45.97 & 0.63 & \\
\hline & 32.31 & 29.99 & 49.12 & 0.61 & \\
\hline & 33.81 & 30.15 & 48.59 & 0.62 & \\
\hline
\end{tabular}

$x$ : Position of neutral axis $\left(d-l_{\text {crack }}\right)$

Comparing to the load between results by heating and analytical results, significant difference was not observed, and fiber contribution in tension can be evaluated by this technique.

\subsection{Shear Capacity of Reinforced FRC (1.0- D13 and 1.5-D13 Series)}

In this section, shear capacity of reinforced FRC beams with D13 rebar, which exhibit shear failure, is discussed through fiber bridging stress.

Figures 6 and 7 illustrate the loaddisplacement curves of 1.0-D13 and 1.5-D13 series, respectively. There was significant difference between the load before heating and that after heating, as shown in Table 5 . In these specimens, shear failure was observed, and diagonal shear crack was observed.

Fiber contribution can be calculated by following equation.

$$
V_{\mathrm{fd}}=\left(F_{\mathrm{t} \_ \text {residual }} / \tan \beta \mathrm{u}\right) * b_{\mathrm{w}} * d
$$

$V_{\text {fd: }}$ Shear capacity by fiber

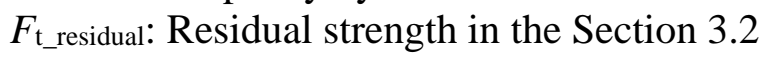

$\beta$ u : Crack angle (45 degrees)

$b_{\mathrm{w}}$ : Width of specimen

$d$ : Effective depth

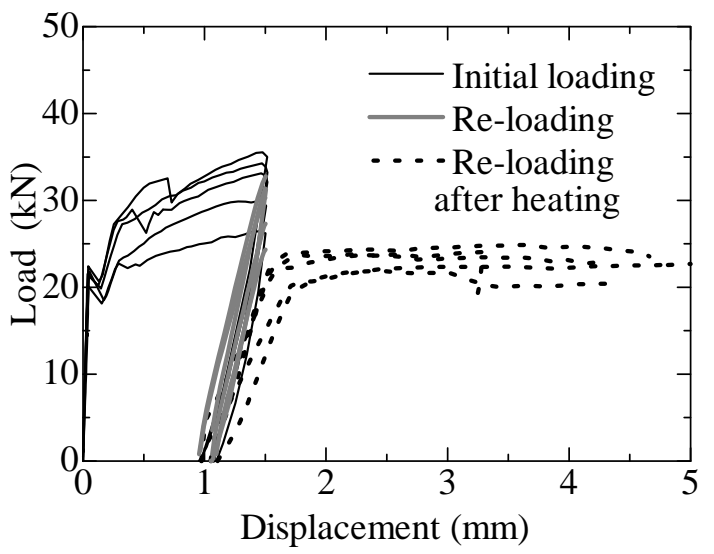

Figure 4: Load-displacement curves of 1.0-D6 Series.

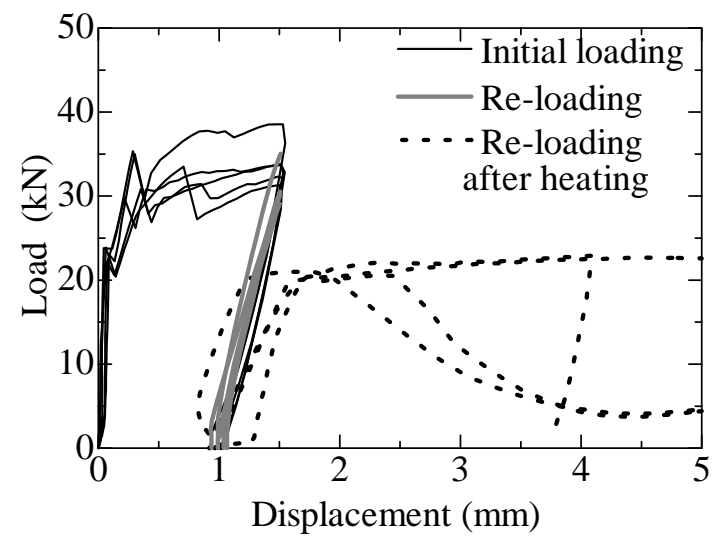

Figure 5: Load-displacement curves of 1.5-D6 Series. 
Table 5: Residual strength of FRC with D13 rebar (shear failure)

\begin{tabular}{|c|c|c|c|c|}
\hline Series & $\begin{array}{l}\text { Exp. fiber } \\
\text { contribution } \\
(\mathrm{kN})\end{array}$ & $\begin{array}{c}\text { Cal. Fiber } \\
\text { contribution } \\
V_{\text {fd }} \text { in } \\
\text { Eq.(3) }(\mathrm{kN})\end{array}$ & Exp./Cal. & Averaged \\
\hline \multirow{5}{*}{ 1.0-D13 } & 30.6 & \multirow{5}{*}{13.1} & 2.34 & \multirow{5}{*}{2.24} \\
\hline & 29.2 & & 2.23 & \\
\hline & 37.9 & & 2.89 & \\
\hline & 27.0 & & 2.06 & \\
\hline & 22.2 & & 1.70 & \\
\hline \multirow{5}{*}{ 1.5-D13 } & 39.8 & \multirow{5}{*}{21.0} & 1.90 & \multirow{5}{*}{1.62} \\
\hline & 32.0 & & 1.53 & \\
\hline & 34.5 & & 1.64 & \\
\hline & 33.0 & & 1.57 & \\
\hline & 30.8 & & 1.47 & \\
\hline
\end{tabular}

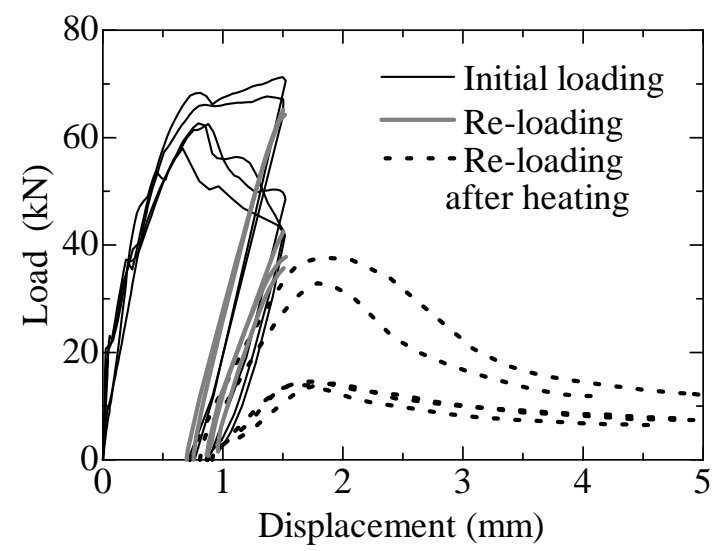

Figure 6: Load-displacement curves of 1.0-D13 Series.

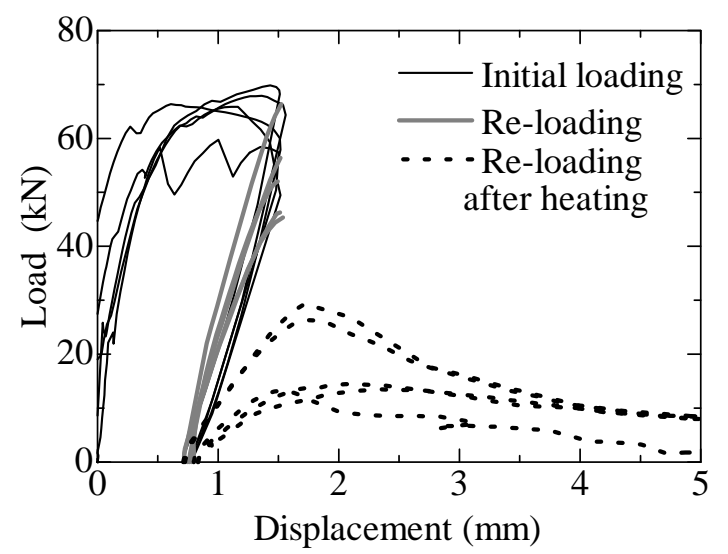

Figure 7: Load-displacement curves of 1.5-D13 Series.
The obtained values $V_{\mathrm{fd}}$ through the above equation are shown in Table 5 , in addition to the experimental values obtained by heating process. The experimental value was about two times higher than calculated value. In the case of 1.0-D13 series, significant difference was observed comparing to $1.5-\mathrm{D} 13$ series. It seems that the fiber bridging stress in equation (2) is assumed to be constant along an assumed crack. However, it seems that there is a gradient in stress along a crack experimentally. In the case of 1.5-D13 series, descending branch in softening region was not steep, and this material response agrees with the assumption of the equation.

\section{CONCLUSIONS}

This paper presents an experimental approach to clarifiy the fiber contribution of FRC in flexural and shaer failure, and following conclusions were obatained.

(1) Fiber bridging stress of FRC with PP fibers was extracted by heating process experimentally.

(2) Evaluated fiber bridging stress of FRC, which exhibits flexural failure, obtained by heating process well agreed with value in design. 
(3) In the specimen with shear failure, the experimental fiber contribution obtained by heating process was about two times higher than calculated value.

To interpret the fiber bridging mechanism, further experiments are needed.

\section{REFERENCES}

[1] Adebar, P. et al. 1997. Shear tests of fiber reinforced concrete beams without stirrups, ACI Structural Journal, 94(1): 68-76.

[2] Japan Society of Civil Engineers. 2008. Recommendations for Design and Construction of High Performance Fiber Reinforced Cement Composites with Multiple Fine Cracks, Concrete Engineering Series. 